\title{
Forecasting yield and tuber size of processing potatoes in South Africa using the LINTUL-Potato-DSS model
}

\author{
A.T.B. Machakaire* a,b , J.M. Steyn ${ }^{\text {a }}$, D.O. Caldiz ${ }^{d}$, A.J. Haverkort ${ }^{a, c}$ \\ ${ }^{a}$ Department of Plant and Soil Sciences, University of Pretoria, Private Bag X20, Hatfield 0028, South Africa \\ ${ }^{b}$ McCain Foods SA (Pty) Ltd, P.O. Box 1023, Delmas, 2210, South Africa \\ ${ }^{c}$ Plant Research International, Wageningen University and Research Center, P.O. Box 616, 6700 AP Wageningen, The \\ Netherlands \\ d Global Agronomy R\&D, McCain Foods Limited, Ruta 226 Km 61,500 B7620EMA Balcarce, Argentina \\ *allan.machakaire@mccain.co.za
}

\section{ABSTRACT}

The LINTUL-Potato-DSS model uses the linear relationship between radiation intercepted by the crop and radiation use efficiency (RUE), to calculate dry matter production. The model was developed into a yield forecasting system for processing potatoes based on long term and actual weather and crop data. The model outcome (Attainable yield, Yatt) was compared to actual yields (Yact) of a summer crop in South Africa and the ratio Yact:Yatt was used for forecasting yield in winter crops. Results showed that accurate forecasts ( $<20 \%$ variation between the actual and forecasted values) could be produced already early in the growing season and that for cultivar Innovator, actual and forecasted yields were well correlated $(r=0.797)$. Forecasted and observed yields at harvest were not significantly different at the $5 \%$ level, $P=0.637$ (t-test). Forecasts of tuber number using LINTULPotato-DSS were not accurate in the present study and further research is needed on this aspect. It is concluded that the model is a valuable management tool that can be used to produce accurate 
forecasts of tuber yield from as early as 8 weeks before final harvest. Since the model was tested with only one cultivar grown in three different growing regions of South Africa, further evaluation using different cultivars and localities is recommended.

\section{Keywords}

Yield forecasting, LINTUL-Potato-DSS model, radiation use efficiency, dry matter, processing potatoes

\section{Introduction}

Growers who produce potatoes for processing aim at high yields ( $>50 \mathrm{t} \mathrm{ha}^{-1}$ for South African conditions) and quality at the lowest costs. When proper cultivars are grown under suitable conditions, supplied with the adequate amounts of inputs, high yields can be achieved. However, high yields do not necessarily lead to the best quality because recovery at the factory level mainly depends on high dry matter content (DMC), and uniform and relatively large tuber sizes. Both yield and quality of potato tubers are influenced by various yield determining, limiting and reducing factors (Haverkort and Struik 2015).

Crop growth models have previously been used to investigate the effects of management options such as planting dates, population density, irrigation timing and frequency, and fertiliser applications in different environmental conditions on crop growth and yield (Molahlehi et al. 2013; Svubure et al. 2015). Therefore, simulation models could potentially also be useful to help improve yield forecasts for the potato processing industry. LINTUL-Potato-DSS is an example of such a model that has been successfully calibrated and validated for different potato production environments around the world (Kooman and Haverkort 1995; Caldiz et al. 2001; Franke et al. 2011; Haverkort et al. 2015). Haverkort et al. (2015) showed how to use the LINTUL-Potato-DSS model to forecast yield anytime 
during the growing season by using real time weather data until the current day in the season and long term historical weather data to forecast the yield at any future date.

Some of the earlier developed models such as the one developed by Sands et al. (1979) were weak as they did not give reliable estimates of emergence and they also used the same functions of temperature for all growth and development phases. In LINTUL-Potato-DSS, emergence is estimated from a sprout growth rate of $0.7 \mathrm{~mm}\left({ }^{\circ} \mathrm{Cd}\right)^{-1}$ with a base temperature of $0{ }^{\circ} \mathrm{C}$. Many crop growth models do not currently include factors that can potentially limit the growth and yield of crops grown under field conditions. LINTUL-Potato-DSS calculates attainable yields under water-limiting conditions and also estimates soil water holding characteristics such as field water capacity and wilting point based on the soil silt + clay content, which are input parameters for the model. The SUCROS model of Van Keulen et al. (1982) calculates crop growth from light extinction in the canopy, photosynthesis and respiration, and does not include water limitation. Griffin et al. (1993) observed that the SUBSTOR-Potato v2.0 model performs poorly when simulating leaf area index (LAI) which potentially results in over-estimation of yield. In LINTUL-Potato-DSS, the extinction coefficient was replaced by a direct conversion of LAI into the proportion of intercepted solar radiation by green foliage (Haverkort et al., 2015). The model of Fishman et al. (1985) considered irrigation as the only source of soil water, whereas LINTUL-Potato-DSS also considers rainfall, with $80 \%$ of it being assumed to infiltrate into the soil and available for crop use.

The objective of the current study was to test the hypothesis that a simple crop model using real-time current and long term historical weather data can be used to accurately forecast potato yields in an industrial setting. To this end it was necessary to derive a ratio between modelled attainable yield and the actual yield, and to apply this ratio to future yield predictions. This ratio gives an indication of how successful growers are in achieving attainable yields under local conditions. 


\section{Materials and methods}

\section{Experimental work}

The field data for yield forecasting was collected from Lichtenburg in the North West Province of South Africa during the 2013 summer season, and from Dendron, Vivo, Soekmekaar and Marble Hall in Limpopo Province during the 2014 winter season (Figure 1). Cultivar Innovator is one of the main cultivars used by one of the processing companies in South Africa and is grown in these production areas. Two sets of weather data were required to run the model, average long term data ( 7 years for

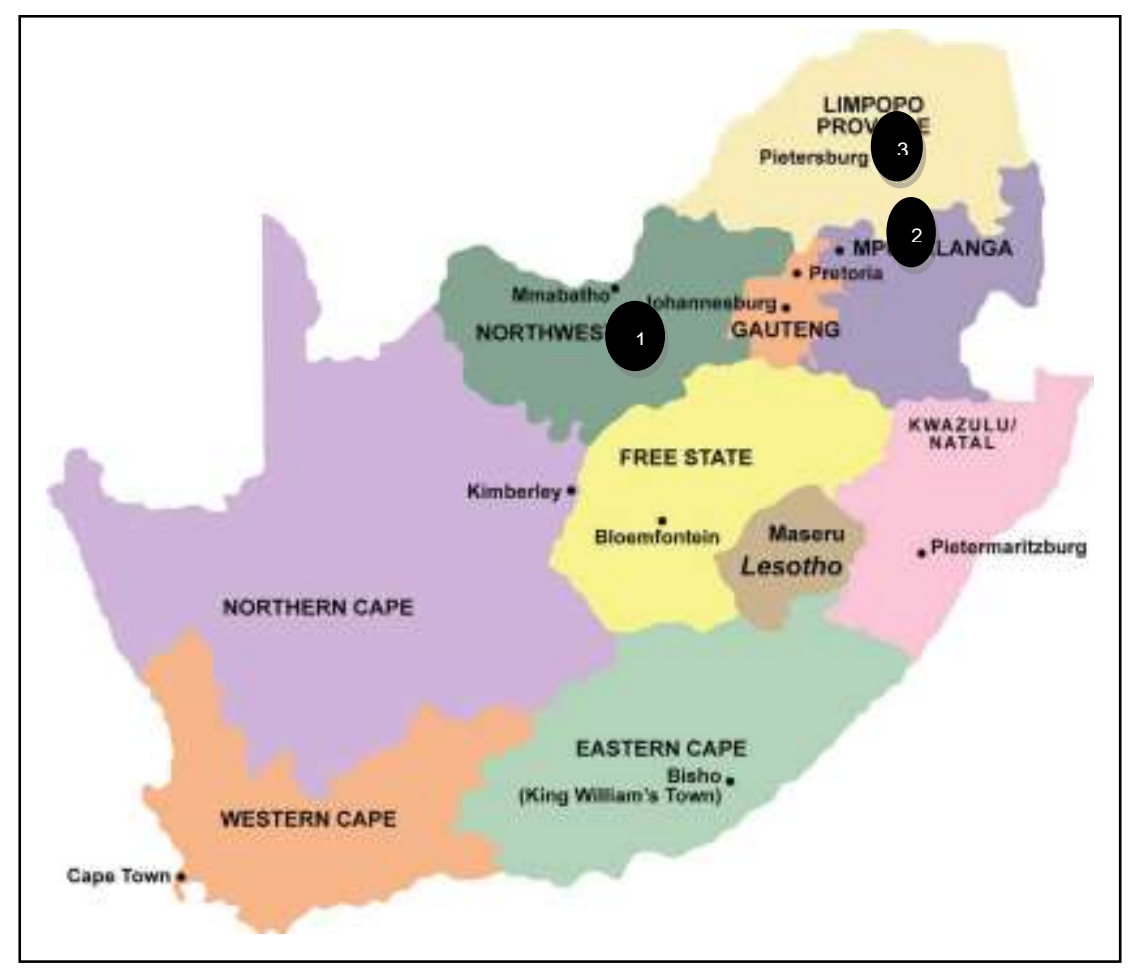

Fig. 1 Map showing the study areas in South Africa $(1=$ Lichtenburg, $2=$ Marble Hall, $3=$ Dendron/Vivo/Soekmekaar)

Lichtenburg, and 11 years for Dendron, Vivo, Soekmekaar and Marble Hall) and the actual seasonal weather data for each area, which was obtained from weather stations located in the different production areas (Table 1). The following weather variables required by the model were recorded: 
average of daily maximum and minimum temperatures, average daily solar radiation, total evapotranspiration and rainfall.

Table 1: Name and location of weather stations (production area in brackets) used in yield forecasting for the different production areas.

\begin{tabular}{lccc}
\hline Location & Latitude $\left({ }^{\circ} \mathbf{S}\right)$ & Longitude $\left({ }^{\circ} \mathrm{E}\right)$ & Altitude (m.a.s.I.) \\
\hline Lichtenburg & 26.226 & 26.236 & 1,489 \\
\hline Marble Hall & 25.026 & 29.366 & 846 \\
\hline Urk (Vivo) & 23.150 & 29.859 & 849 \\
\hline Uitdraai (Soekmekaar) & 23.708 & 29.478 & 817 \\
\hline Sandput (Dendron) & 23.273 & 29.135 & 1,120 \\
\hline
\end{tabular}

One field at Lichtenburg grown with cultivar. Innovator was selected for destructive sampling during the 2013 summer season. The field was planted on 10 November 2013 and harvested on 11 March 2014. Emergence and plant canopy development data were collected from six plots $\left(2.7 \mathrm{~m}^{2}\right.$ each) marked in this field. Stem, leaf and tuber samples were collected at 23 and 52 days after planting (DAP), and then thereafter fortnightly until harvest; dry mass was determined from +/-300 g subsamples after placing them in an oven at $70{ }^{\circ} \mathrm{C}$ for at least $48 \mathrm{~h}$ or until constant mass. During the 2014 winter season, 10 independent fields grown with cultivar Innovator were selected in Dendron, Vivo, Soekmekaar and Marble Hall production areas. The fields were planted on different dates in the season between the months of February and July. Tuber samples were collected from six plots (2.7 $\mathrm{m}^{2}$ each) marked in each field at final harvest for assessing the actual yield. Tuber samples were also collected from three plots $\left(2.7 \mathrm{~m}^{2}\right.$ each) during the growing season from five of these 10 fields to assess the tuber numbers (count) per $10 \mathrm{~kg}$ sample for tuber size forecasts. Actual yield at the time of sampling was determined from the collected samples. 


\section{LINTUL model simulations}

The LINTUL-Potato-DSS crop growth model simulates potential and water limited attainable crop yield (Haverkort et al., 2015). Weather and management input data collected was used in the model to produce simulations for the entire growing season for development of ground cover, total dry matter accumulation and fresh tuber yield from planting to harvest. Management input data included date of planting, planting depth and day when haulm killing was performed. The standard parameters in LINTUL-Potato-DSS were used.

The sequence of events in LINTUL-Potato-DSS (Haverkort et al., 2015) is based on the original LINTUL-Potato model published by Kooman and Haverkort (1995). Crop development starts at planting, where planting depth, sprout growth rate and effective temperature determine the time it will take the crop to emerge. Thereafter, LINTUL-Potato-DSS assumes that $100 \%$ ground cover (i.e. when $100 \%$ of solar radiation is intercepted by the crop) is achieved at 650 day degrees after emergence. Henceforward, canopy closure (100\% ground cover) is assumed until crop end. The harvest index is set at 0 at tuber initiation, which occurs 1 to 3 weeks after emergence, depending on the earliness of the cultivar, and reaches 0.75 at crop end (maturity). Radiation use efficiency (RUE) is set at $1.25 \mathrm{~g} \mathrm{MJ}^{-1}$ intercepted solar radiation. However, when the daily average temperature (Tave) is below $3 \circ \mathrm{C}$, RUE equals 0 . RUE increases linearly from 0 to $1.25 \mathrm{~g} \mathrm{MJ}^{-1}$ between Tave of 3 and 15 $\circ \mathrm{C}$ and remains constant until Tave reaches $20 \circ \mathrm{C}$. Due to excessive respiration at unfavourably high temperatures, RUE decreases linearly from $1.25 \mathrm{~g}$ to $0 \mathrm{~g} \mathrm{MJ}^{-1}$ between Tave of 20 and $28 \circ \mathrm{C}$, and becomes 0 when Tave $>28 \circ \mathrm{C}$ (Haverkort et al., 2015).

Crops in the present study were grown under centre pivot irrigation and also received rainfall during the season. The model assumes that $50 \%$ of the plant available water in the root zone is freely available for uptake by the plants, and when there is rainfall, it is assumed that $80 \%$ thereof infiltrates into the soil and is available for crop use. The soil texture (\% silt and clay) is also part of the model 
input data as it affects crop growth indirectly by influencing the amount of soil available water for crop uptake.

Data from the destructive measurements was used to compare the LINTUL-Potato-DSS model attainable yield (Yatt) values to those of cultivar Innovator under the conditions that prevail in the study area in South Africa (Yact). The resulting ratio between actual yields and calculated attainable yields gives an indication of how efficiently plants make use of the available environment, and was then applied for future yield forecasts. Subsequently, independent data collected from other production areas in a different cropping season using the Yact:Yatt ratio were used in the yield forecast calculations. If forecasts are accurate, then the model can be considered reliable and used for future applications and agro-ecological zoning.

\section{Calculation of actual and attainable yield ratio (Yact:Yatt) to be used as correction factor in yield forecasting}

In calculating the Yact:Yatt ratio, input data collected from field observations, destructive crop growth sampling and current real time weather data during the 2013 growing season were used. For the cultivar Innovator, data collected from field BK2 in Lichtenburg area was used (BK2: S 2558'40.89"; E 25 55'39.10", altitude 1,489 m above sea level). To determine the Yact:Yatt ratio, data was collected from six periodic harvests on the same field, conducted over the growing season. The input data was used to simulate attainable yield throughout the growing season at 23 DAP, 52 DAP and thereafter at approximately 14 day intervals until harvest. Real-time actual seasonal weather data up to the respective sampling day (Table 2) was used for these growth estimates. The simulated attainable yields at specific intervals were compared with observed yields obtained from field samples at the same intervals and dates. The model simulated yields were the attainable yields (or exploitable yield as defined by Van Ittersum et al. 2013), whilst the actual yields were those observed and 
Table 2: Crop sampling details in the 2013 summer season

\begin{tabular}{ccccc}
\hline Sample & Sampling date & DAP $^{*}$ & Sample area $\left(\mathrm{m}^{-2}\right)$ & Replicates \\
\hline 1 & 4 Dec 2013 & 23 & 2.7 & 6 \\
\hline 2 & 2 Jan 2014 & 52 & 2.7 & 6 \\
\hline 3 & 16 Jan 2014 & 66 & 2.7 & 6 \\
\hline 4 & 29 Jan 2014 & 79 & 2.7 & 6 \\
\hline 5 & 12 Feb 2014 & 93 & 2.7 & 6 \\
\hline 6 & 26 Feb 2014 & 107 & 2.7 & \\
\hline *DAP, days after planting & & & \\
\hline
\end{tabular}

${ }^{\star D A P}$, days after planting.

obtained from the field samples. Based on comparisons between the model simulated attainable yield (Yatt) and the actual observed yield (Yact) at each sampling date throughout the growing season, the Yact:Yatt ratios were calculated. This ratio represents the percentage of the attainable yield, as determined by the model that was actually achieved under field conditions. The average of these six ratios was later used to estimate the final yield, based on future yield forecasts.

\section{Yield forecast calculations}

Independent crop, field, and weather data from fields in a different production region and season was used for yield forecasting calculations. The fields used were in the Marble Hall, Soekmekaar, Dendron and Vivo production areas, which are adjacent localities within the same production region of Limpopo province. Cultivar Innovator was grown on 10 different fields in the 2014 winter season and data from these fields was used in the forecast calculations (Table 3). Samples were taken from the various fields at different stages in the growing season. The (fresh) tuber yields expected at final harvest was forecasted on 65 DAP (Table 4). The potato processing industry needs to at least know 
Table 3: Field details for yield forecasting (2014 winter season)

\begin{tabular}{|c|c|c|c|c|c|c|c|c|}
\hline Field Name & $\begin{array}{l}\text { Production } \\
\text { area }\end{array}$ & $\begin{array}{l}\text { Latitude } \\
\left({ }^{\circ} \mathrm{S}\right)\end{array}$ & $\begin{array}{l}\text { Longitude } \\
\left({ }^{\circ} \mathrm{E}\right)\end{array}$ & $\begin{array}{l}\text { Cultivar } \\
\text { planted }\end{array}$ & $\begin{array}{l}\text { Planting } \\
\text { date }\end{array}$ & $\begin{array}{l}\text { Crop end } \\
\text { date }\end{array}$ & $\begin{array}{l}\text { Planting } \\
\text { depth (cm) }\end{array}$ & $\begin{array}{l}\text { Soil clay } \\
\text { (\%) }\end{array}$ \\
\hline M.Hall_L & Marble Hall & $24^{\circ} 56.721$ & $29^{\circ} 21.069$ & Innovator & 6-Jun-14 & $6-$-Oct-14 & 18 & 15 \\
\hline Veeplaas & Marble Hall & $24^{\circ} 59.315$ & $29^{\circ} 09.852$ & Innovator & 7-Jul-14 & $27-O c t-14$ & 15 & 18 \\
\hline M.Hall_R & Marble Hall & $24^{\circ} 57.387$ & $29^{\circ} 14.306$ & Innovator & 19-Jun-14 & 3-Nov-14 & 15 & 18 \\
\hline Soutpansberg & Vivo & $23^{\circ} 06.109$ & $29^{\circ} 29.188$ & Innovator & 18-Jun-14 & 7-Oct-14 & 15 & 20 \\
\hline Vivo_P & Vivo & $22^{\circ} 51.592$ & $29^{0} 09.460$ & Innovator & 21-May-14 & 23-Sept-14 & 18 & 25 \\
\hline Vivo_E & Vivo & $23^{\circ} 04.913$ & $29^{\circ} 07.297$ & Innovator & 20-Jun-14 & 7-Oct-14 & 15 & 20 \\
\hline Dendron_II & Dendron & $22^{\circ} 31.091$ & $28^{\circ} 43.923$ & Innovator & 24-Feb-14 & 9-Jun-14 & 15 & 15 \\
\hline SMK_B & Soekmekaar & $23^{\circ} 28.599$ & $29^{\circ} 56.468$ & Innovator & 20-May-14 & 25-Sept-14 & 15 & 18 \\
\hline SMK_M & Soekmekaar & $23^{\circ} 26.503$ & $29^{\circ} 53.081$ & Innovator & 9-Jun-14 & 14-Oct-14 & 15 & 15 \\
\hline SMK_D & Soekmekaar & $23^{\circ} 27.672$ & $29^{\circ} 57.869$ & Innovator & 27-May-14 & 16-Sept-14 & 15 & 15 \\
\hline
\end{tabular}


Table 4: Summary of fresh tuber yield results at harvest for Innovator in the 2014 winter season.

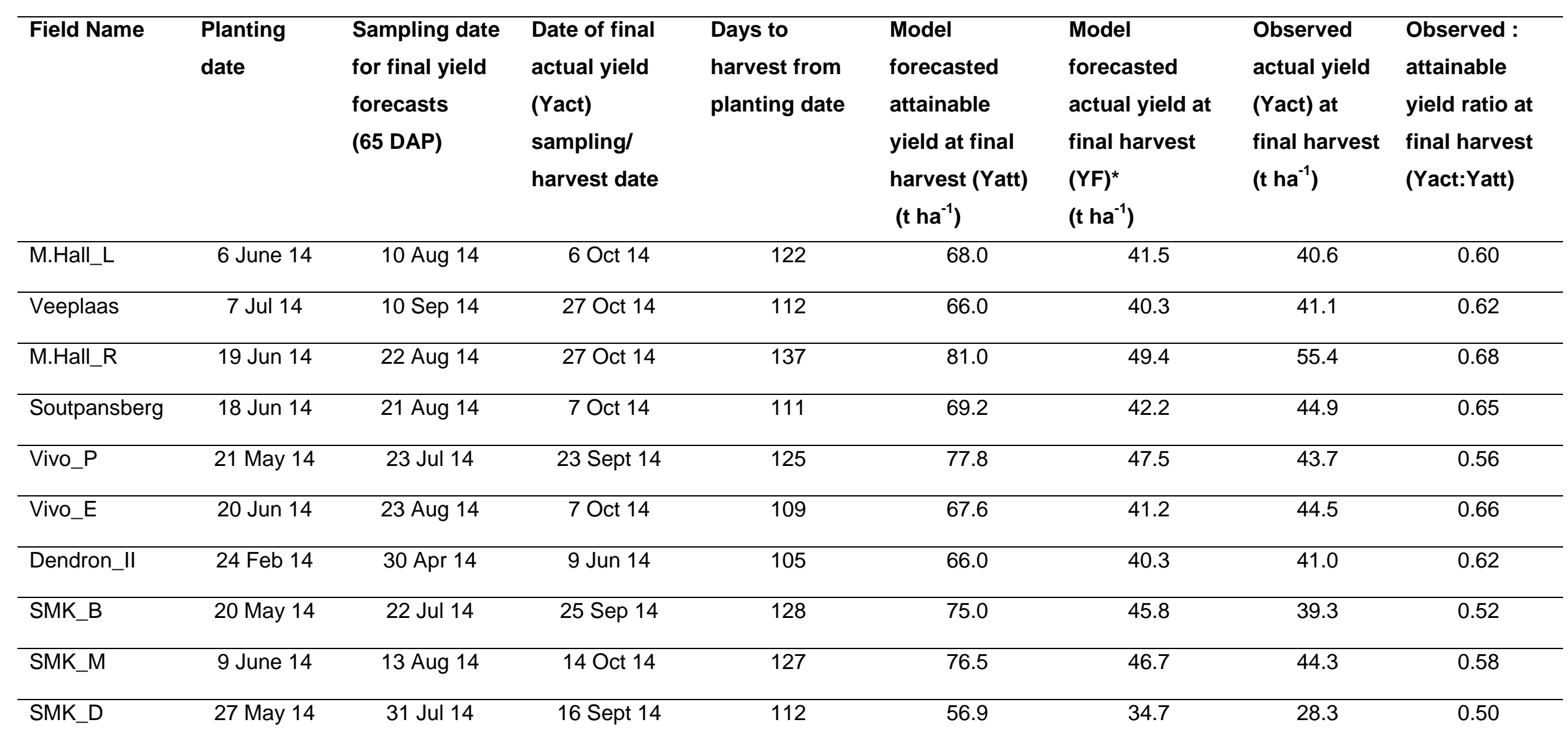

NOTE: * Model forecasted YF = model forecasted Yatt x Yact:Yatt ratio of 0.61 (obtained for cultivar Innovator in the 2013 summer season)

Forecast date was at 65 DAP 
what yields to expect from as early as 6 to 8 weeks before harvest in order to properly plan for harvest, transport and receiving logistics. The chosen 65 DAP used in the forecasting corresponds well to this time period for the particular cultivar used in the study. At 65 DAP the required field and weather data (see below) for each field was then entered into the LINTUL-Potato-DSS model in order to simulate the final yield for each field.

The forecasted attainable yield at final harvest (Yatt) was simulated using actual weather data from planting until 65 DAP, and long term weather data (for the specific production area) for the remainder of the growing season up to harvest (Table 4). Forecasted actual yield (YF) for each field was calculated by multiplying the model forecasted Yatt with the average Yact:Yatt ratio of 0.61 , which was obtained in the 2013 summer season. The model forecasted actual yield at harvest (YF) was then compared with the observed Yact. A t-test was used to assess whether there were significant differences between the forecasted and observed final tuber yield values at the $5 \%$ level.

\section{Tuber number (count) forecasts}

Prediction of tuber size at the end of the crop season using LINTUL-Potato-DSS requires an assessment of tuber number at a sampling point during the season. Samples were collected from five fields in the 2014 winter growing season and the field in the 2013 season to assess tuber numbers (or counts) at that stage. On the day of assessment, the actual tuber count (CA) per $10 \mathrm{~kg}$ sample and actual tuber yield (Yact) were assessed. The forecasted final yield at crop end (YF) was also calculated using the model. The forecasted final tuber count per $10 \mathrm{~kg}$ sample (FCF) at crop end was then calculated as: FCF $=\mathrm{CA} \times($ Yact:YF). A paired sample t-test was used to compare the FCF and actual tuber count per $10 \mathrm{~kg}$ sample at final harvest (CF) at the $5 \%$ level. 


\section{Results}

\section{Growth analysis}

The development of plant biomass as crop growth progressed during the 2013 summer season followed a typical sigmoidal pattern that declined sharply towards the end of the season (Figure 2a), while tuber yield increased gradually until maximum yield was achieved (Figure 2b). The observed fresh tuber yields (Yact) from the six sampling events were regressed against the model simulated attainable yields (Yatt) and they correlated closely, with $r=0.97$ (Figure 3a). The RMSE and MAE values were high at $25.98 \mathrm{t} \mathrm{ha}^{-1}$ and $20.60 \mathrm{t} \mathrm{ha}^{-1}$, respectively. The observed (Yact, from physically collected samples) and modelled attainable fresh tuber yields (Yatt) differed throughout the growing season (from 53 to $122 \mathrm{DAP}$ ), confirming that the model predicts higher attainable yields and a correction factor is needed in order to predict reliable actual yields for yield forecasting purposes.

\section{Yield forecasting}

For yield forecasting the Yact:Yatt ratio calculated for cultivar Innovator was 0.61 (61\%). This was the average of the Yact:Yatt ratios for the six sampling events in the 2013 summer season. As this ratio was obtained from only one crop grown in one production region, it is recognized that further work would be required to confirm its validity. The forecasted final fresh tuber yields (YF) of different independent fields growing during the 2014 winter season compared reasonably well with the observed fresh tuber yields (Yact) at final harvest, with $r=0.797$ (Figure 3b). The standard deviation

of the paired differences from the t-test was $4.14 \mathrm{t} \mathrm{ha}^{-1}$. On some farms, the model over-estimated final yields, whilst on others yields were under-estimated, and it was accurate on three farms. It was 

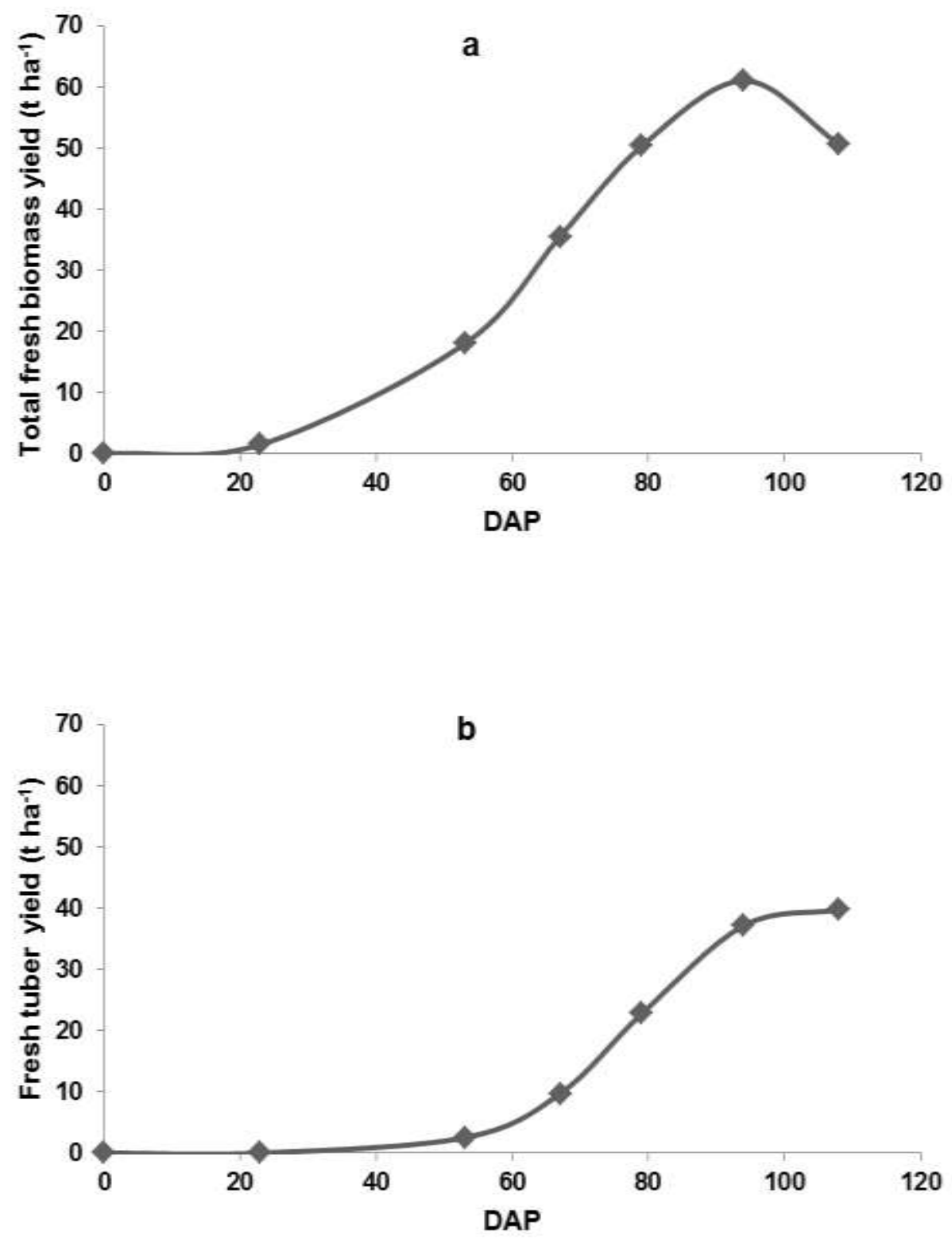

Fig. 2 a) Total fresh biomass yield and b) fresh tuber yield development in the 2013 summer season. 

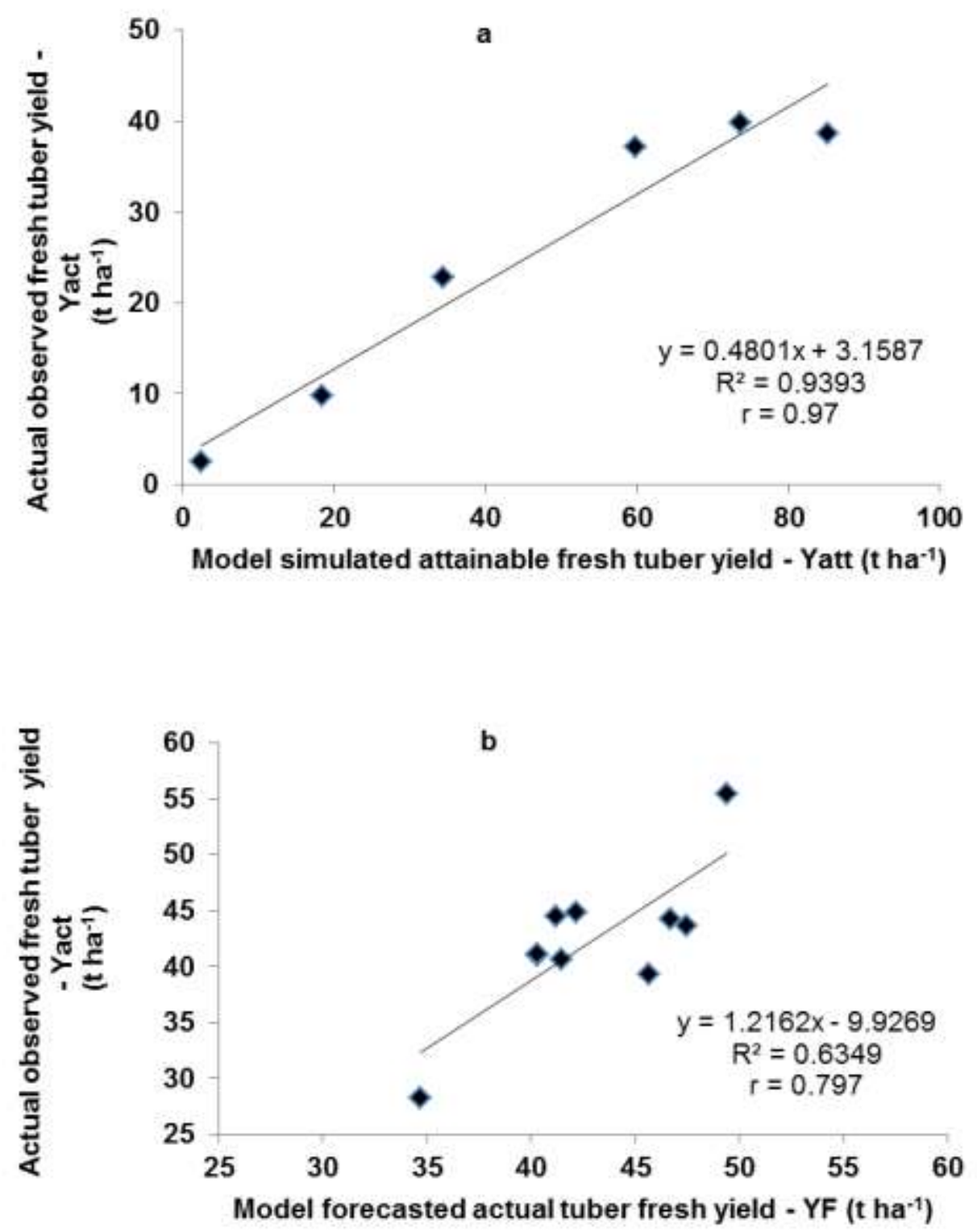

Fig. 3 Correlation between a) Model simulated attainable yield (Yatt) and actual observed fresh tuber yield (Yact) for cultivar Innovator from 53 to 122 DAP during the 2013 summer season, b) Model forecasted actual yield (YF) and actual observed fresh tuber yield (Yact) for different fields at final harvest in the 2014 winter season.

observed that the model tended to under- or over-estimate yields under situations where the crop was subjected to prolonged periods of water stress (field SMK_D) or frost damage (Fields M.Hall_R and Vivo_P). The RMSE and MAE values were relatively low at $3.98 \mathrm{t} \mathrm{ha}^{-1}$ and $3.34 \mathrm{t} \mathrm{ha}^{-1}$, respectively, 
Table 5: Summary of tuber number (count) forecast data in the 2013 summer and 2014 winter seasons.

\begin{tabular}{|c|c|c|c|c|c|c|c|}
\hline Field & $\begin{array}{c}\text { DAP at } \\
\text { Assessment }\end{array}$ & $\begin{array}{l}\text { DAP at } \\
\text { Final } \\
\text { harvest }\end{array}$ & $\begin{array}{l}\text { Actual yield on } \\
\text { assessment date } \\
\text { (Yact) } \\
\left(\mathrm{t} \mathrm{ha}^{-1}\right)\end{array}$ & $\begin{array}{c}\text { Model } \\
\text { forecasted } \\
\text { actual } \\
\text { final yield } \\
\text { (YF) } \\
\left(\text { t ha }^{-1}\right)\end{array}$ & $\begin{array}{c}\text { Actual tuber } \\
\text { number per } 10 \\
\text { kg sample on } \\
\text { assessment day } \\
\text { (CA) }\end{array}$ & $\begin{array}{l}\text { Forecasted final } \\
\text { tuber number } \\
\text { per } 10 \mathrm{~kg}(\mathrm{FCF})^{\star}\end{array}$ & $\begin{array}{l}\text { Actual final tuber } \\
\text { number per } 10 \\
\text { kg } \\
\text { (CF) }\end{array}$ \\
\hline SM (2013) & 79 & 120 & 23 & 51 & 95 & 43 & 55 \\
\hline SMK_B (2014) & 105 & 128 & 27 & 45 & 128 & 78 & 97 \\
\hline SMK_M (2014) & 85 & 134 & 22 & 54 & 168 & 67 & 89 \\
\hline SMK_D (2014) & 98 & 151 & 22 & 60 & 159 & 60 & 82 \\
\hline M.Hall_R (2014) & 109 & 130 & 32 & 47 & 111 & 77 & 76 \\
\hline Dendron_II (2014) & 91 & 120 & 21 & 59 & 188 & 67 & 94 \\
\hline
\end{tabular}

Note: ${ }^{*} \mathrm{FCF}=$ Forecasted final tuber count per $10 \mathrm{~kg}$ sample (FCF $=\mathrm{CA} \times($ Yact:YF) 
indicating that there was low error in the comparison. The $p$-value of 0.64 for the paired data point comparisons between actual final observed fresh tuber yield (Yact) and model forecasted fresh tuber yield (YF) samples from each field indicated that the final observed yields were not significantly different $(p>0.05)$ from the model forecasted yields at the $5 \%$ significance level.

\section{$\underline{\text { Tuber number (count) forecast }}$}

The forecasted tuber numbers per $10 \mathrm{~kg}$ sample (FCF) at final harvest were generally lower than the actual observed tuber number per $10 \mathrm{~kg}$ sample (CF), with the exception of the field M.Hall_R. The better agreement for the latter field may have been because this field was assessed much closer to final harvest in comparison to the other fields (Table 5). The actual yield (Yact) was observed to be usually two thirds of the model calculated yield (Table 4), suggesting that tuber number will be overestimated by around $30 \%$. A paired samples t-test showed significant differences between the FCF and CF at the $95 \%$ confidence level.

\section{Discussion and conclusions}

In comparing the LINTUL-Potato-DSS model outcome, attainable fresh tuber yields for cultivar Innovator correlated well with the actual observed fresh tuber yields of various independent fields, with a correlation coefficient of 0.797 . The $R^{2}$ value of 0.635 suggests a good fit of the regression line to the data points. Yield forecasts produced at 65 DAP, which corresponded to approximately 8 weeks before harvest of an average potato crop, closely matched the actual fresh tuber yields obtained at crop end. The results showed that expected actual fresh tuber yields at harvest can be forecasted with reasonable accuracy (less than $20 \%$ variation between forecasted and actual yields) from as early as 8 weeks before harvest. One challenge of using the model is that it forecasts attainable and water-limited yields whilst under practical field conditions there are other yield limiting and reducing factors (pests and diseases, nutrients and crop management) that affect the actual final 
yield. Hence, there is a need to develop methods to account for yield reduction factors in order to better estimate the actual yield from the attainable yield. A limitation of the study was the fact that data from only one field was available for estimating the Yact:Yatt ratio, which may not be representative of a wide range of growing conditions .

Apart from weather conditions, other factors, such as management and growing conditions can influence potato growth and ultimately the accuracy of yield forecasting which are responsible for the Yact:Yatt ratio being lower than 1. This study has shown that reasonable accurate predictions of potato crop growth and yield for the processing industry are possible from as early as eight weeks before harvest, with the use of the LINTUL-Potato-DSS crop growth simulation model. Tuber number forecasts in this trial were not accurate and this issue needs further attention in future research.

There is a need to carry out more Yact:Yatt calculations for more potato cultivars and other production regions and seasons in South Africa with different climatic conditions. The data used for forecasting in the 2014 winter season of this study, was collected from 10 fields which achieved Yact:Yatt ratios that ranged from 0.50 to 0.65 (Table 4). Varying management conditions on the different farms could have influenced the ratios, with higher ratios achieved on the better managed fields. However, in spite of the observed variation, the average of the ratios across the 10 farms (Table 4) was 0.60 , which is close to the ratio of 0.61 recorded in the 2013 summer season. This study produced preliminary data for use of the model to forecast final tuber sizes from in-season tuber count assessments and final yield forecasts, but there is need for further work to improve the accuracy of such forecasts.

\section{Acknowledgements}

The authors thank Dr. Ben Pieterse of McCain Foods South Africa for his support and also the McCain Company and its growers in South Africa for allowing the use of data collected for this study. 


\section{References}

Caldiz DO, Gaspari FJ, Haverkort AJ, Struik PC (2001) Agro-ecological zoning and potential yield of single or double cropping of potato in Argentina. Agricultural and Forest Meteorology 109:311-320. doi:10.1016/S0168-1923(01)00231-3

Fishman S, Talpaz H, Winograd R, Dinar M, Arazi Y, Roseman Y, Varshavski S (1985) A model for simulation of potato growth on the plant community level. Agricultural Systems 18:115-128. doi: $10.1016 / 0308-521 \times(85) 90049-6$

Franke AC, Steyn JM, Ranger KS, Haverkort AJ (2011) Developing environmental principles, criteria, indicators and norms for potato production in South Africa through field surveys and modelling. Agricultural Systems 104:297-306. doi:10.1016/j.agsy.2010.12.001

Griffin TS, Johnson BS, Ritchie JT (1993) A simulation model for potato growth and development: Substor-potato Version 2.0. Michigan State University, Department of Crop and Soil Sciences

Haverkort AJ, Struik PC (2015) Yield levels of potato crops: Recent achievements and future prospects. Field Crops Research 182: 76-85.

Haverkort AJ, Franke AC, Steyn JM, Pronk AA, Caldiz DO, Kooman PL (2015) A robust potato model: LINTUL-POTATO-DSS. Potato Research 58: 313-327.

Kooman P, Haverkort AJ (1995) Modelling development and growth of the potato crop influenced by temperature and day length: LINTUL-POTATO. Potato ecology and modelling of crops under conditions limiting growth. In: Current Issues in Production Ecology 3:41-59. Springer. doi:10.1007/978-94-011-0051-9_3 
Molahleli L, Steyn JM, Haverkort AJ (2013) Potato crop response to genotype and environment in a subtropical highland agro-ecology. Potato Research 56:237-258. doi:10.1007/s11540-013-9241-1

Sands PJ, Hackett C, Nix HA (1979) A model of the development and bulking of potatoes (Solanum Tuberosum L.). Field Crops Research 2:309 - 331. Doi.10.1016/0378-4290(79)90031-5

Svubure O, Struik PC, Haverkort AJ, Steyn JM (2015) Yield gap analysis and resource footprints of Irish potato production systems in Zimbabwe. Field Crops Research 178:77-90. doi:10.1016/j.fcr.2015.04.002

Van Ittersum MK, Cassman KG, Grassini P (2013) Yield gap analysis with local to global relevance A review. Field Crops Research 143: 4-17.

Van Keulen H, Penning de Vries F, Drees EM (1982) A summary model for crop growth. Penning de Vries, FWT, Laar, HH eds 87-98. 